\title{
An overview of gambling in Nigeria
}

\author{
Chinyere Mirian Aguocha ${ }^{1}$ and Sanju George ${ }^{2}$ ()
}

${ }^{1}$ Consultant Psychiatrist and Senior Lecturer (Psychiatry), Department of Internal Medicine, Imo State University, Owerri, Nigeria

${ }^{2}$ Professor of Psychiatry and Psychology, Rajagiri School of Psychology, Rajagiri School
Behavioural Sciences and Behavioural Sciences and
Research, Rajagiri College of Research, Rajagiri College of
Social Sciences (Autonomous), Kochi, India.

Email: sanjugeorge531@gmail. com

Keywords. Gambling; Nigeria; policy; research; public health.

First received 25 Nov 2019 Final revision 9 May 2020 Accepted 13 May 2020

\section{doi:10.1192/bji.2020.28}

(C) The Author(s) 2020. This is an Open Access article, distributed under the terms of the Creative Commons Attribution licence (http://creativecommons.org/ licenses/by/4.0/), which permits ( and reproduction in any medium, provided the original work is properly cited.

\begin{abstract}
Gambling, legal and illegal, is popular in Nigeria. Lack of stringent regulation and enforcement, coupled with the rise in online gambling opportunities, has resulted in increased gambling-related harm. There needs to be a multipronged public health strategy to address the harms of gambling and for this the government, gambling industry, policy makers and academic experts need to engage in a meaningful debate.
\end{abstract}

Nigeria is Africa's most populous country, with a population of about 185 million people. It is the seventh most populated country in the world and is also the world's twentieth largest economy. Nigeria gained independence from the British in 1960 and has since been governed by civilian leaders and military dictators. Nigeria is currently governed by a democratically elected party but is troubled by religious fundamentalist groups.

In this brief paper, we will present an overview of the gambling landscape of Nigeria.

\section{Gambling in Nigeria}

Gambling has always existed in Nigeria but in the past it was viewed as an antisocial activity and was actively discouraged by the church, which warned against the quest for quick wealth. In the late 1990s, in Chapter 22, section 236 of the Criminal Code Act, the Nigerian government legalised certain forms of gambling in an attempt to generate tax revenues. ${ }^{1}$ This has made gambling more acceptable to the public, especially to the underaged. ${ }^{2}$ The most popular forms of gambling in present-day Nigeria are online sports betting (e.g. football league promotions and the pools), the lottery and slot machines. ${ }^{3}$ Many Nigerians view gambling as a harmless leisure activity: a recent study of the Nigerian general population found that $36 \%$ of adult respondents had gambled and 53\% of these people were daily gamblers. ${ }^{4}$ However, some argue that problem gambling in Nigeria, in the near future, will be a greater public health problem than substance misuse. Illegal gambling, especially betting on football, is extremely popular in Nigeria, although its precise scale is unknown. It is surprising that, despite the nature and scale of this problem, gambling and its related harms have not been adequately researched in Nigeria.

\section{Gambling laws in Nigeria}

Gambling in Nigeria is regulated by the National Lottery Regulatory Commission. The National
Lottery was legalised in Nigeria in 2005, under the National Lottery Act $2005 .{ }^{5}$ The law distinguishes between games of skill (which are legal) and games of chance (which are illegal). Legal forms of gambling include the lottery, land-based casinos and sports betting, whereas roulette, dice games and non-skilled card games are considered illegal. There is no specific provision in the law to regulate online gambling. The minimum legal age to be able to gamble in Nigeria is 18 years.

\section{Gambling research from Nigeria}

Gambling research in Nigeria has been mainly focused on the prevalence, pattern and determinants of gambling among the different subpopulations in the country. ${ }^{2,3,6}$ A significant relationship has been reported with age, gender, financial strain, some personality factors and depression., It has been argued that monetary gain, fuelled by greed, unemployment, economic hardship and poverty are the most potent motivating factors for gambling and may act as a spring board to fuel criminality. ${ }^{4}$ Other less important factors are the pursuit of enjoyment, passion for sports and peer group influence. ${ }^{4}$ Friends who engage in gambling, gambling to gain the acceptance of friends, parental gambling and problems with authorities on account of gambling have been reported as important predictors of gambling. ${ }^{2}$ Studies carried out to determine attitudes towards and perception of gambling found that, although gambling was perceived as a risky activity, it was believed to yield high returns and was thus perceived as a means of earning money quickly. ${ }^{8}$ In spite of the laws regulating gambling in Nigeria, about $57.2 \%$ of school-age children have gambled at least once in their lifetime and $77.6 \%$ of these have gambled in the past year, with $58.3 \%$ reporting unfettered access to gambling dens. ${ }^{2}$

\section{Treatment services for problem gamblers in Nigeria}

Problem gambling refers to continuous, uncontrollable gambling despite harmful negative consequences. ${ }^{9}$ There are no specialist treatment centres for problem or pathological gamblers in Nigeria. As awareness of gambling problems is limited among the public and among healthcare and allied professionals, most people with gambling-related issues go unrecognised and untreated. Those in whom it is identified as a problem get addiction treatment from existing substance use treatment centres and specialists. To the best of our knowledge, no Gamblers Anonymous meetings take place anywhere in 
Nigeria. The few very wealthy Nigerians who have gambling problems seek specialist addiction treatment, including therapy in rehabilitation clinics overseas.

\section{The way forward: problem gambling merits a public health prevention approach}

Harms from problem gambling are multiple and often not as direct and visible as in substance addictions. A range of harms that adversely affect the individual, the family and society have been reported. These include uncontrolled gambling, sometimes fuelled by desperate attempts to win back money, financial difficulties and extreme poverty; disruption of relationships within the family, with loss of trust and failure to carry out expected responsibilities; engagement in other risky behaviours, such as excessive drinking, substance use and crime. ${ }^{10}$ Despite most forms of gambling being illegal in Nigeria, substantial amounts are spent on a daily basis. ${ }^{4}$ The rate of problem gambling is estimated to range from 1 to $8 \%$, with $10-15 \%$ at risk of problems related to gambling. ${ }^{11,12}$ With the increasing influence of the West and the fast-paced technological penetration in Nigeria, it is anticipated that problems related to gambling will increase. Unfortunately, prevention approaches are currently almost non-existent.

It is against this background that it is pertinent to conceptualise an appropriate public health response to gambling in Nigeria.

We propose a three-tiered framework for such a public health response: primary, secondary and tertiary. Primary prevention focuses on preventing or postponing initiation of the first bet. Primary preventive approaches aim to make the general public aware of the risks and potential negative consequences of excessive gambling and to help them make decisions about 'responsible' gambling. This should be targeted mainly at preventing under-age gambling and protecting other vulnerable groups. Concerted efforts have to be made to develop age verification processes to prevent under-age online gambling. Community awareness campaigns on the dangers of gambling, together with funding and disseminating research on gambling, have to be carried out. Voluntary contributions, a statutory levy imposed on the gambling industry or the industry taking these up as part of their corporate social responsibility should be used to fund these. Regulation of advertisements and promotions of gambling by regulating the types of advert and disclosing during adverts the risks inherent in gambling, and incorporating into the civic education curriculum of primary and secondary schools the dangers of gambling, are also desirable. Government should regulate the density of gambling outfits that can be set up in a particular location and sites where they are permitted to operate. Government recognising that gambling is a public health problem, with policy development and responsibility domiciled in the Ministry of Health, would go a long way in helping this materialise. Current regulations that ban under-age gambling have to be strictly enforced by the appropriate regulatory authority. For adults who gamble, responsible gambling should be promoted. It is here that perhaps Nigeria's policy makers could look West: one example is Britain's Responsible Gambling Strategy Board, an independent panel of experts that advises the government on aspects related to responsible or safe gambling.

Secondary prevention should screen for potential problems in those already initiated into gambling. Secondary prevention measures target 'at-risk' and problem gamblers. It aims to ensure early diagnosis and treatment for the individual by raising awareness of healthcare professionals about gambling and by breaking down barriers to treatment-seeking. It also involves the gambling industry's self-regulation to ensure reduced harm to their clients. Clinics for treating those with gambling problems should be set up in government hospitals, and health workers in primary health clinics should be trained in the identification of problem gambling, with an appropriate referral pathway set up.

Tertiary prevention strategies include specialised psychological and other treatment interventions for gamblers and their families.

Finally, from a public health point of view, other important parameters that would help quantify the problem of gambling include the following: the rates of various psychosomatic symptoms (cardiovascular, musculoskeletal, gastrointestinal and other non-specific psychosomatic symptoms) and psychiatric problems such as depression, anxiety, substance misuse and personality disorders among problem gamblers; financial problems such as debt and bankruptcy; gambling-related crime; and interpersonal relationship problems such as neglect of the family, domestic violence and child abuse. Much more research is called for into measuring or estimating the above-noted health and social costs borne by society.

\section{Conclusions}

There needs to be a wider debate about gambling as a public health issue in Nigeria, involving key stakeholders such as academics, healthcare professionals, policy makers and the gambling industry. Positive action is required to minimise gambling-related harm to the people of Nigeria.

\section{Author contributions}

Both authors contributed to the conception of the idea and to its writing.

\section{Declaration of interest}

\section{None.}

ICMJE forms are in the supplementary material, available online at https://doi.org/10.1192/bji.2020.28.

\section{References}

1 Criminal Code Act, Laws of the Federation of Nigeria 1990: Chapter 22. Government of Nigeria, 2005 (http://www. commonlii.org/ng/legis/num_act/cca115/). 
2 Aguocha CM, Durum CB, Newton EC, Amado KU, Loose EO, Give MN. Determinants of gambling among male students in secondary schools in Imo State, Nigeria. J Subst Use 2018; 24: 199-205.

3 Oyebisi EO, Alao KA, Popoola BI. Gambling behaviour of university students in south-western Nigeria. IFE Psychologia 2012; 20(1).

4 NOIPolls. New poll reveals rising trend of gambling in Nigeria: betting and gambling in Nigeria (15 Aug). NOIPolls, 2017 (https://noi-polls.com/new-poll-reveals-rising-trend-of-gamblingin-nigeria).

5 Nigerian National Lottery Act 2005. National Lottery Trust Fund, 2005 (http://nltf.gov.ng/wp-content/uploads/2018/02/NationalLottery-Act.pdf).

6 Abdulbaqi SZ, Tejideen TO, Raji, KO, Ajisegbede AO. Gambling among residents of Ilorin Metropolis: a study of causative factors. Ilorin J Hum Resour Manage 2019; 3: 2.

7 Temitope BE, Oyekola A, Mary BA. Personality Traits and financial strain as determinants of gambling behaviour among youth in Nigeria: a case study of youths in Oyo State and Ekiti State. Am Int ] Soc Sci Res 2019: 4(1): 1-8.
8 Aguocha CM, Duru CB, Nwefoh EC, Ndukuba AC, Amadi KU, Olose EO. Attitudes towards and perception of gambling among secondary school students in a developing country. Int Gamb Stud 2019; 19: 532-44.

9 World Health Organization. The ICD-10 Classification of Mental and Behavioural Disorders. Research and Diagnostic Criteria. World Health Organization, 1993.

10 Adenugba A, Akhuetie R, Umeokoro I. The determinants and effects of gambling culture on youths in Nigeria: the case of the city of Ibadan. Afr J Soc Sci 2018; 8: 104-18.

11 National Research Council. Pathological Gambling: A Critical Review. National Academy Press, 1999.

12 Reilly C. The prevalence of disordered gambling behavior in the United States: three decades of evidence. In Gambling and the Public Health (Part 1) (ed National Center for Responsible Gambling): 3-11. NCRG, 2009 (http://www.ncrg.org/ sites/default/files/uploads/docs/monographs/ncrg_monograph_ vol3.pdf).

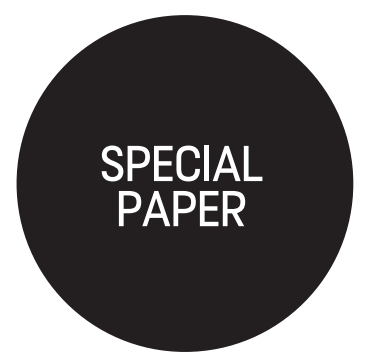

\title{
Gambling in Malaysia: an overview
}

\author{
Balan Rathakrishnan ${ }^{1}$ and Sanju George ${ }^{2}$ ๑
}

${ }^{1}$ Associate Professor, Faculty of Psychology and Education, Malaysia University of Sabah (UMS), Kota Kinabalu, Malaysia. Email: rbhalan@ums.edu.my

${ }^{2}$ Professor of Psychiatry and Psychology, Rajagiri School of Behavioural Sciences and Research, Rajagiri College of Social Sciences (Autonomous), Kochi, Kerala, India. Email: sanjugeorge531@gmail.com

Keywords. Gambling; law: Malaysia; research.

First received 13 May 2020 Accepted 17 Sep 2020

doi:10.1192/bji.2020.55

Copyright @ The Author(s), 2020 Published by Cambridge University Press on behalf of the Royal College of Psychiatrists. This is an Open Access article distributed under the terms of the Creative Commons

Attribution licence (http://creative commons.org/licenses/by/4.0/), which permits unrestricted re-use, distribution, and reproduction in any medium, provided the original work is properly cited.

\section{Many forms of gambling are legal and popular in Malaysia. Despite this, in Malaysia, research into gambling is limited and there is no coherent strategy to tackle gambling-related harms. This paper summarises the gambling landscape of Malaysia, law governing gambling and research done so far and gives some recommendations on the way forward.}

Malaysia is a South East Asian country with a population of approximately 32.37 million people. Malaysia gained independence from the British Empire in 1963. Islam is the predominant religion (61.3\%), followed by Buddhism (19.8\%), Christianity (9.2\%) and Hinduism (6.3\%), and the rest practice traditional Chinese religions. ${ }^{1}$ Gambling is forbidden under Islamic law (Sharia law) so most Muslims do not engage in legal gambling. As Malaysia has a multi-ethnic population, with Malay making up 63\%, Chinese making up approximately $25 \%$ and those with Indian ancestry making up $12 \%$ of the total 32.37 million population, it is these latter groups who gamble more through legal means and who spend more on gambling. ${ }^{2,3}$

'Gambling disorder' sits alongside the more traditional substance addictions in DSM-5. In ICD-11, the ICD-10 term 'pathological gambling' is replaced by 'gambling disorder'.

\section{Gambling in Malaysia}

It would appear that gambling was 'brought' to Malaysia by Chinese merchants in the 19th century. Gambling, both legal and illegal forms, is very popular in Malaysia. ${ }^{4}$ Some forms of gambling, such as lotteries, casino games and horse racing, are legal in Malaysia, whereas all forms of sports betting (at bookmakers) and online gambling are illegal. Gambling is legal only if a license or permit has been granted by the authorities the Unit Kawalan Perjudian (Betting Control Unit) of the Ministry of Finance. Lotteries in Malaysia are allowed under the Lotteries Act 1952. Currently, there are six legal lotteries (all privately owned) in Malaysia). Alongside these, there exist several illegal lottery businesses and it was estimated that in 2018 'Malaysia's illegal lottery business generated about 60 percent more revenue than the six legal operators combined' ${ }^{5}$

There is only one legal land-based casino in Malaysia. This privately owned casino was set up in the 1970s in a very 'Las Vegas style' and is open $24 \mathrm{~h}$ a day but denies entry to Muslims and those under 21 years of age. This casino offers over 400 types of electronic table games, 3000 slot machines and 30 tables with games such as blackjack, tai sai, roulette and boule.

Horse racing was introduced in Malaysia by the British during the 1800s and currently there are three racecourses and betting on horses is 